\title{
Bioactive Psiadia punctulata Trachylobane Diterpenes Against Mastitis Pathogens
}

\author{
Wanjau OM${ }^{1 *}$, Mahungu SM⿻上丨 and Matasyoh JC ${ }^{\mathbf{1}}$ \\ ${ }^{1}$ Department of Chemistry, Faculty of Science, Egerton University, Kenya \\ ${ }^{2}$ Deparment of Dairy and Food Science, Faculty of Agriculture, Egerton University, \\ Nakuru, Kenya \\ *Corresponding Author: Wanjau OM, Department of Chemistry, Faculty of Science, \\ Egerton University, Kenya.
}

DOI: $10.31080 /$ ASNH.2020.04.0653

\author{
Received: February 21, 2020 \\ Published: February 26, 2020 \\ (C) All rights are reserved by Wanjau OM., \\ et al.
}

\begin{abstract}
Bacterial pathogens are a major challenge and a constant drawback in the management of both human and animal health. The dairy farmer may suffer huge losses due to infection of the udder of dairy cows with mastitis. Manifestation of mastitis in dairy cows occurs, resulting from poor personnel hygiene, unsuitable environment, unhygienic milking procedure or use of contaminated milking equipment and supplies. At times managerial measures have failed to give significant success, and use of post milking teat dipping solutions has been applied with success.

The presence of a leaf surface exudate on Psiadia punctulata is supposedly for a purpose, and this, coupled with the traditional uses for the plant warrant bioassay directed phytochemical studies on the plant.

Column chromatography of concentrated cold acetone leaf wash of Psiadia punctulata using silica gel; serially eluting the column with ethyl acetate-hexane mixtures, yielded two trachylobane diterpenoid compounds, PP5 and PP6 as clear crystalline compounds. In vitro bioassay tests applying the disc diffusion method and the agar diffusion methods using levofloxacin and chloramphenicol as positive controls found the trachylobane diterpenoid compounds to be active against Staph aureus and Salmonella typhi. Structural characteristics of the diterpenoid compounds were evaluated through phytochemical tests and correlation of proton and carbon- 13 NMR spectra. The presence of antimicrobial agents in acetone leaf wash of Psiadia punctulata, active against Staph aureus and Salmonella typhi makes the plant invaluable as a source of a home remedy in eradication of mastitis manifestation in dairy cows.

Keywords: Psiadia punctulate; Antimicrobial; Trachylobane Diterpenes; Mastitis, Staph aureus and Salmonella typhi
\end{abstract}

\section{Introduction}

Mastitis, also known as udder inflammation, is a common problem in dairy herds and causes huge economic losses in the dairy industry [1]. Staphylococcus aureus, Escherichia coli and Streptococcus uberis are the main mastitis-causing pathogens [2]. More antimicrobial agents must be identified to replace some of the antimicrobial drugs that have developed drug resistance due to extensive use, misuse and overuse of antimicrobials in both human and animal health. Staphylococcus aureus is also one of the most frequent causal agents of lower respiratory tract infections. Methicillin-resistant S. aureus (MRSA) is of particular concern in the United States since approximately $60 \%$ of all staphylococcal infections in the ICU are caused by MRSA [3].

Plants are a reservoir of antimicrobial substances which are not only potent against target pathogens but also seem to stand a better chance to overcome the onslaught of microbial resistance mechanisms [4].

The medicinal value of plants lies in the ability of their constituent compounds to produce physiological action in the human body [5]. The most important of these bioactive compounds include alkaloids, terpenoids, steroids, flavonoids, tannins and phenolic compounds [6]. Leaf decoctions of Psiadia punctulata have been used as a remedy for colds, headache and abdominal pains [7]. Maasai use the leaf decoction to get rid of fleas from calves [8] (Henke, 1994) while a report by Maurice., et al. (1999) [9] details on the use of the leaf decoction of Psiadia punctulata for the treatment of venereal diseases and as a tonic.

The genus Psiadia belongs to the family Compositae (Asterace$a e$ ). It is a shrub that is draught resistant and is widely spread in the arid regions of the Rift valley, Eastern region and the drier parts of central Kenya. Its leaves have a shiny look and develop a sticky feel soon after they have been plucked due to the presence of some leaf exudate which is found as $24 \%$ dry leaf weight [10]. The constituent compounds of leaf surface exudate [11] supposedly serve some protective role on the plant [12].

Meena Shamrao Deogade., et al. (2016) [13] reported antimicrobial activity of a methanol extract of fresh leaves of Ocimum tenuiflorum Linn. against Escherichia coli, Staphylococcus aureus and Klebsiella pneumonia at $20 \mathrm{mg} / \mathrm{ml}$, corresponding to inhibition zones of $8 \mathrm{~mm}, 16 \mathrm{~mm}$ and $11 \mathrm{~mm}$ respectively. Shruthi., et al. (2012), [14] working on Murraya Koenigii observed antibacterial activity in ethanol extract at $12.43 \mathrm{mg} / \mathrm{ml}$ for Klebsiella pneumonia and $9.23 \mathrm{mg} / \mathrm{ml}$ for Salmonella typhimurium. Acetone leaf extracts of nine plant species (Elisha., et al. 2017) [15] were active against 
Escherichia coli, Salmonella typhimurium and Pseudomonas aeruginosa at MIC levels ranging between 0.04 and $0.32 \mathrm{mg} / \mathrm{ml}$. Methanol root extract Clerodendrum myricoides (Hochst.) R. Br. ex Vatke, locally known as "Munjuga-iria" in Mbeere community of Embu County in Kenya was active against methicillin resistant $S$. aureus (MRSA) at MIC level of $15.3 \mu \mathrm{g} / \mathrm{ml}[16]$.

\section{Plant materials}

The resinous leafy branches of $P$. punctulata were harvested in the neighborhood of lake Elementaita, about 35 kilometers east of Nakuru town, Kenya, at an altitude of 1,670 m. A voucher specimen is available at the National Museum of Kenya Herbarium.

\section{Extraction}

Leaves were detached from the branches of $P$. punctulata plant and were stuffed into a 5L erlmeyer flask while fresh, up to a weight of $1 \mathrm{Kg}$. for extraction. A 1.5 liter portion of cold acetone was introduced into the flask and shaken for two minutes and decanted as an orange solution [4,17]. Two more fresh portions of acetone were used to wash the leaves clear of the orange exudate. Extracted leaves were allowed to dry in open air to a constant weight of 438g. The acetone extract was decanted and filtered through some glass wool into a 2.5L Winchester bottle. The acetone was recovered using a rotary evaporator and the concentrate was preserved in an open brown glass bottle $(100 \mathrm{ml})$ and stored in a vacuum desiccator until a constant weight of $47.5 \mathrm{~g}$ of concentrate $(10 \% \mathrm{wt}$. of dry extracted leaves) was attained.

\section{Chromatographic methods}

$10 \mathrm{~g}$ of the extract was introduced into a glass column $(4.5 \mathrm{~cm}$ diameter), packed with 230 - 400 mesh silica gel up-to a height of $27 \mathrm{~cm}$. The column was sequentially eluted with $500 \mathrm{ml}$ portions of $15 \%, 20 \%, 40 \%, 50 \%$ and $100 \%$ ethylacetate in hexane [18]. The eluant was collected as $40 \mathrm{ml}$ fractions from which pure compounds were isolated through fractional crystallization from acetone-hexane mixtures. Anisaldehyde spray solution was used as the locating reagent on TLC plates developed in 8:2 ethylacetatehexane solvent mixture. Melting points (uncorrected) were determined using a Gallen camp melting point apparatus. $1 \mathrm{H}$ and $13 \mathrm{C}$ NMR spectra were determined at 500 and 125 MHZ, respectively.

Identification of the compounds was achieved through correlation of spectral data, melting point values and reference to literature data [19].

\section{Antimicrobial disc diffusion tests}

Tests for antibacterial activity for pure compounds and the crude plant extract were carried out using the agar disk diffusion assay [20]. Agar medium was prepared from commercially available dehydrated base according to the manufacturer's instruction. The media was reconstituted at $120^{\circ} \mathrm{C}$ for $15-20$ minutes in an autoclave, after which it was immediately allowed to cool in a water bath maintained at $45-50^{\circ} \mathrm{C}$. The freshly prepared and cooled medium was poured into disposable plastic flat-bottomed petri dishes to give a uniform depth of approximately $5 \mathrm{~mm}$. The agar medium was allowed to cool at room temperature and stored at $2-8^{\circ} \mathrm{C}$. A representative sample of each batch was examined for sterility by incubating at $37^{\circ} \mathrm{C}$ for 24 hours.

\section{Preparation of discs}

Discs for the drug sensitivity test were prepared by punching discs of $6 \mathrm{~mm}$ diameter using Whatman filter paper No.1. The discs were dispensed into a screw capped glass bottle and sterilized by dry heat in a hot air oven at $180^{\circ} \mathrm{C}$ for 2 hours.

\section{Preparation of antimicrobial test solutions}

Levofloxacin (500 mg) was used as positive control at concentration levels of $10 \mathrm{ppm}, 5 \mathrm{ppm}$ and. $2.5 \mathrm{ppm}$. One tablet (500 mg) was dissolved in cold DMSO: $\mathrm{H}_{2} \mathrm{O}$ mixture in the ratio of 1:5 to make a $1000 \mathrm{ml}$ stock solution of $500 \mathrm{ppm}$. $2 \mathrm{ml}$ of the $500 \mathrm{ppm}$ stock solution were diluted to $100 \mathrm{ml}$ to give $10 \mathrm{ppm}$ solution. $10 \mathrm{ml}$ and $5 \mathrm{ml}$ of the $10 \mathrm{ppm}$ solution were consecutively diluted to $20 \mathrm{ml}$ in separate volumetric flasks to give $5 \mathrm{ppm}$ and $2.5 \mathrm{ppm}$ solutions respectively.

Test solutions of PP5 and PP6 were prepared by dissolving 10 mg of each into $50 \mathrm{ml}$ of 1:5 DMSO: $\mathrm{H}_{2} \mathrm{O}$ mixture to make stock solutions of $200 \mathrm{ppm}$. Test solutions of $10 \mathrm{ppm}, 5 \mathrm{ppm}$ and $2.5 \mathrm{ppm}$ were prepared through serial dilution of the 200 ppm stock solutions.

Discs treated with the test solutions were placed individually on the inoculated agar plates using the fine sterile forceps. The discs were distributed evenly so that they were no closer than $25 \mathrm{~mm}$ from center to center. Three discs were placed on a plate of $100 \mathrm{~mm}$ in diameter. Within 15 minutes after the discs were applied, the plates were inverted and placed in an incubator set at $37^{\circ} \mathrm{C}$. Results were noted and recorded after an incubation period of 24 hours.

\section{Antimicrobial agar dilution tests}

Varying concentrations of the antimicrobial agents were incorporated in series into agar plates by mixing $2 \mathrm{ml}$ of each dilution with $18 \mathrm{ml}$ of molten agar per plate, at $50^{\circ} \mathrm{C}$. Four holes of $6 \mathrm{~mm}$ in diameter each were perpendicularly dug at evenly spaced positions into the agar mixture after setting. Each well was inoculated with the same volume $(0.1 \mathrm{ml})$ of the standardized suspension of the bacteria under test - Salmonella typhi (1), Staphylococcus aureus (2), Baccilus subtilis (3) and Proteus mirabilis (4). The agar plates were incubated for 24 hours, after which MIC for each drug was determined as the lowest concentration that inhibited bacteria growth.

\section{Results and Discussion}

Column chromatography of the acetone leaf extract using hexane-ethylacetate solvent system mixtures yielded antibacterial trachylobane diterpenoid compounds PP5 and PP6 whose structural data correlate to compounds 1, 2 and 3 in (Figure 1) [21].

Doublets at $\delta 0.6$ and $\delta 0.8$ were characteristic of cyclopropane ring $\mathrm{H}-16$ and $\mathrm{H}-12$ with corresponding carbon resonances at $\delta$ $25.35(\mathrm{C}-16)$ and $\delta 23.53(\mathrm{C}-12)$. 


$\begin{array}{cccc} & \underline{\mathrm{R}}_{1} & \mathrm{R}_{2} & \mathrm{R}_{3} \\ 1 & \mathrm{OH} & \mathrm{H} & \mathrm{OH} \\ 2 & \mathrm{OH} & \mathrm{OH} & \mathrm{OH}\end{array}$

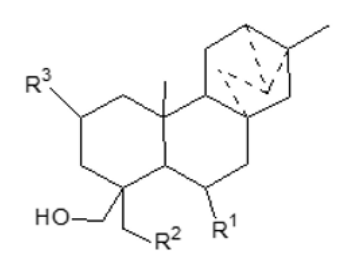

Figure 1: Trachylobane diterpenoid compounds.

HMBC correlation assigned $2 \mathrm{xCH}_{2} \mathrm{OH}$ resonances to $\mathrm{C}-18$ and $\mathrm{C}-19$. One $\mathrm{CHOH}$ resonance to $\mathrm{C}-6$. Figure 2 and figure 3 below demonstrate this.

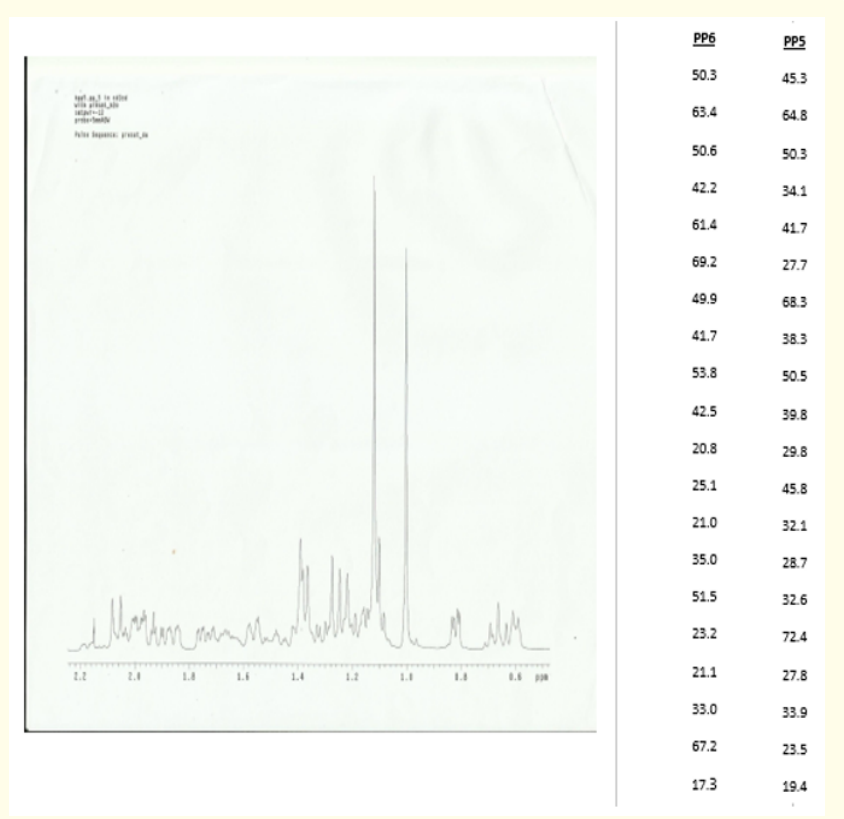

Figure 2

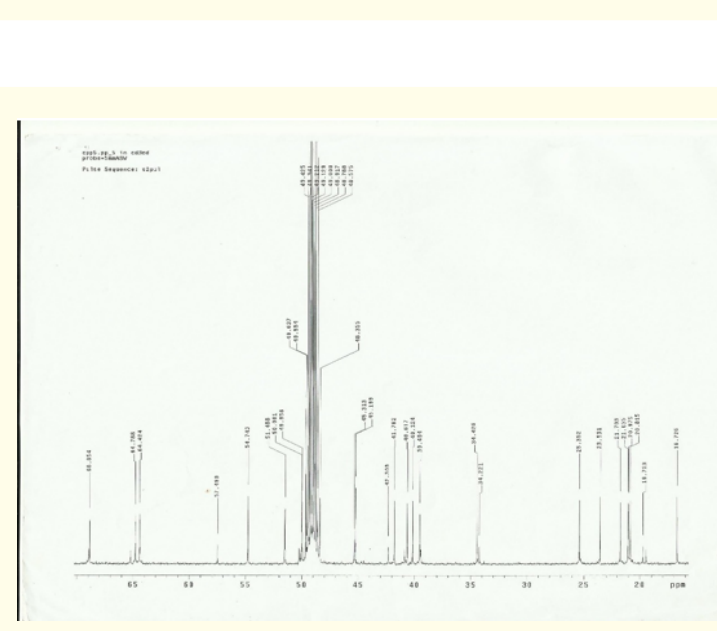

Figure 3

Melting point (uncorrected was determined as $219-220^{\circ} \mathrm{C}$ for PP5 and 180-181 for PP6).
Acetone leave wash of the Psiadia punctulata leave exudate is rich in several secondary metabolites as is revealed on the TLC chromatogram in figure 4 below

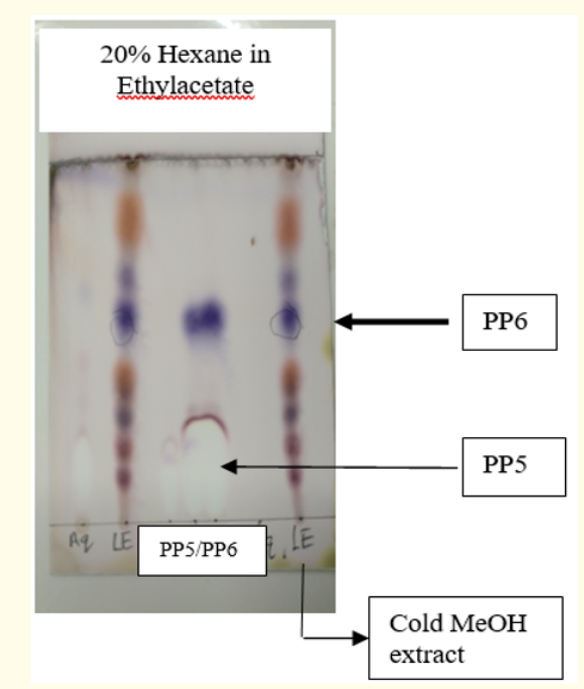

Figure 4

Most of the constituent compounds of the Psiadia punctulata leaf exudate are relatively volatile and their concentrations diminish in boiled aqueous extract (Aq) on the TLC chromatogram.

\begin{tabular}{|l|c|c|c|}
\hline Test Solution & PP5 (diameter) & PP6 (diameter) & $\begin{array}{c}\text { Levoflaxacin } \\
\text { (diameter) }\end{array}$ \\
\hline $10 \mathrm{ppm}$ & $15 \mathrm{~mm}$ & $15 \mathrm{~mm}$ & $10 \mathrm{~mm}$ \\
\hline $5.0 \mathrm{ppm}$ & $15 \mathrm{~mm}$ & $16 \mathrm{~mm}$ & $6 \mathrm{~mm}$ \\
\hline $2.5 \mathrm{ppm}$ & $16 \mathrm{~mm}$ & $15 \mathrm{~mm}$ & $6 \mathrm{~mm}$ \\
\hline
\end{tabular}

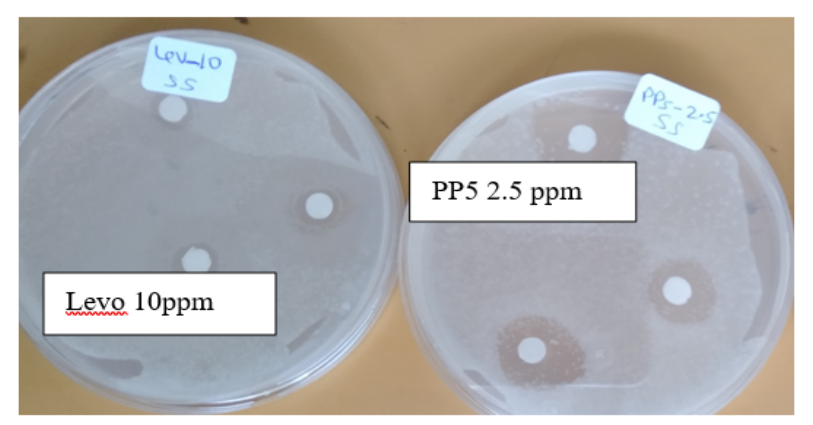

Table 1: Antibacterial activity (diameter in $\mathrm{mm}$ ) against Salmonella typhi (clinical isolate).

PP5 and PP6 were tested for antimicrobial activity against Salmonella typhi (1), Staphylococcus aureus (2), Baccilus subtilis (3) and Proteus mirabilis (4) using the agar dilution method as shown in figure 3 here below. Both PP5 and PP6 demonstrated antimicrobial activity against Salmonella typhi (1) and Staphylococcus aureus (2) at concentration levels of $1.875 \mathrm{ppm}$. Chloramphenicol was used as a positive standard but did not demonstrate inhibition at a concentration level of $250 \mathrm{ppm}$.

Antimicrobial activity reported for Psiadia punctulata methanol extract [22] is definitely due to the presence of the trachylobane diterpenoid compounds. 

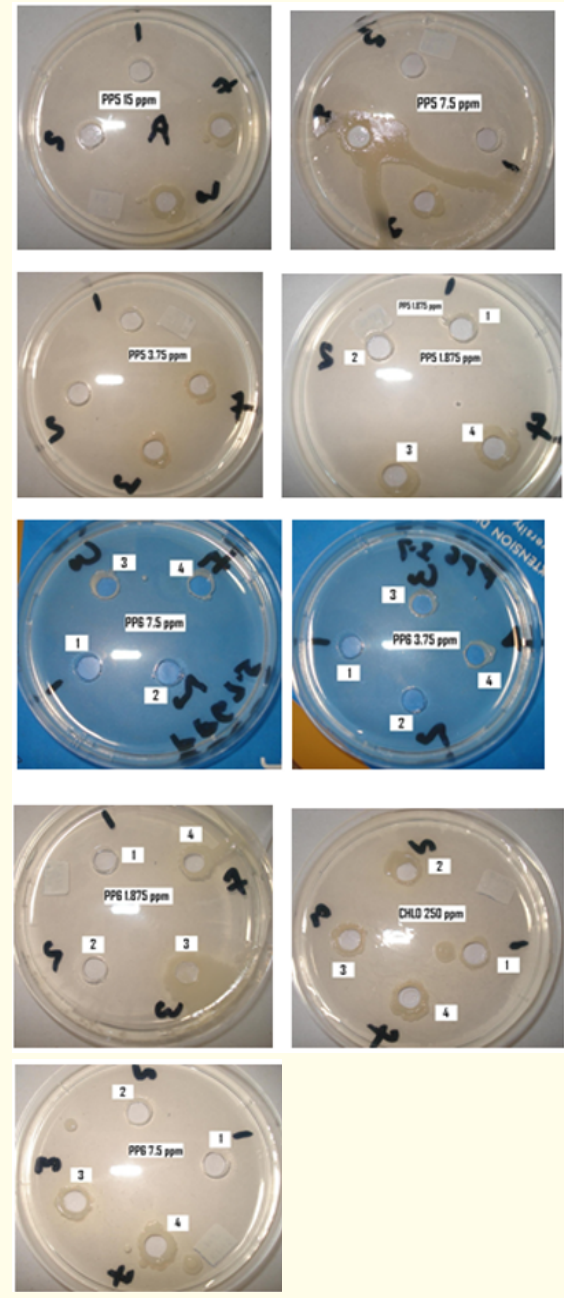

Figure 5: Agar dilution test.

Antimicrobial activity has also been reported for both chloroform and methanol extracts of Larrea tridentata against clinical isolates of Staphylococcus aureus $(\mathrm{n}=25)$ at $\mathrm{MIC}_{80}=125 \mu \mathrm{g} / \mathrm{ml}$ for both extracts [23].

\section{Conclusion}

The present study indicate PP5 and PP6 as effective antimicrobial agents against Staph aureus and Salmonella typhi at concentration levels below $2.5 \mathrm{ppm}$. Clinical trials are required for possible application of the trachyloban diterpenes in the formulation of hand washing soaps and milking salves in the management of mastitis manifestations in dairy cows.

\section{Acknowledgements}

The authors are grateful to the University of Kwa-Zulu Natal and Prof Dulcie Mullholand for support in laboratory space, chemicals and instruments.

\section{Bibliography}

1. Aleksandra Kalinska., et al. "Mastitis pathogens in dairy cattle - a review". World Scientific News 89 (2017): 22-31.

2. Misrak Birhanu., et al. "Prevalence of bovine subclinical mastitis and isolation of its major causes in Bishoftu Town, Ethiopia”. BMC Research Notes 767 (2017).
3. Virgilio Bocanegra-García., et al. "The bioactivity of plant extracts against representative bacterial pathogens of the lower respiratory tract". BMC Research Notes 2 (2009): 95.

4. Kenneth G Ngwoke., et al. "Antimicrobial natural. Products". In book: Science against microbial pathogens: communicating current research and technological Advances. Published by Formatex Spain (2011).

5. Sebastien Block., et al. "Diterpenes from the leaves of Croton zambesicus”. Phytochemistry 65 (2004): 1165-1171.

6. T Mythili and R Ravindhran. "Phytochemical screening and antimicrobial activity of Sesbania sesban (L.)". Asian Journal of Pharmaceutical and Clinical Research 5.4 (2012): 179-182.

7. J Ogweno Midiwo., et al. "Bioactive compounds from some Kenyan ethnomedicinal plants: Myrsinaceae, Polygonaceae and Psiadia punctulate". Phytochemistry Reviews 1 (2002): 311323.

8. Henke (1994).

9. Maurice., et al. (1999).

10. J Ogweno Midiwo., et al. "Flavonoids of Polygonum senegalense part III: Isolation of dihydrochalcone glucoside and quercetin glucosides". Bulletin of the Chemical Society of Ethiopia 8.2 (1994): 79-84.

11. Midiwo JO., et al. "Diterpenes from the leaf exudates of Psiadia punctulate". Phytochemistry 45 (1997): 117-120.

12. Uma BF., et al. "Flavones and phenylpropenoids in the surface exudates of Psiadia punctulate". Phytochemistry 57 (2001): 571-574.

13. Meena Shamrao Deogade., et al. Antibacterial.

14. Shruthi., et al. (2012)

15. Ishaku Leo Elisha., et al. The antibacterial.

16. Sospeter Ngoci Njeru., et al. "Antimicrobial and cytotoxicity properties of the organic solvent fractions of Clerodendrum myricoides (Hochst.) R. Br. ex Vatke: Kenyan traditional medicinal plant". Journal of Intercultural Ethnopharmacology (2016).

17. Wanjau OM., et al. "Antioxidant Activity of Methoxylated Flavonoids in Oils in Deep Frying Processes". Food and Nutrition Sciences 9 (2018): 1273-1284.

18. Sergio R Ambrosio., et al. "Antibacterial Activity of Kaurane Diterpenes". Zeitschrift für Naturforschung 63 (2008): 326D330.

19. World Health Organization. Antimicrobial drug resistance report by Secretariat. Executive Board EB134/37, 134th Session 6 December (2013). 
20. J Ochei and A Kolhatkar. Antimicrobial susceptibility tests in Medical Laboratory Science Theory and Practice (2007): 789810.

21. JO Midiwo., et al. (1997b)

22. Ramzi AA., et al. "Assessment of selected Yemeni Medicinal plants for their in vitro antimicrobial, anticancer and antioxidant activities". Pharmaceutical Biology 49.2 (2011): 200-210.

23. Virgilio Bocanegra-García., et al. (2009b).

\section{Assets from publication with us}

- Prompt Acknowledgement after receiving the article

- Thorough Double blinded peer review

- Rapid Publication

- Issue of Publication Certificate

- High visibility of your Published work

Website: https://www.actascientific.com/

Submit Article: https://www.actascientific.com/submission.php Email us: editor@actascientific.com

Contact us: +919182824667 